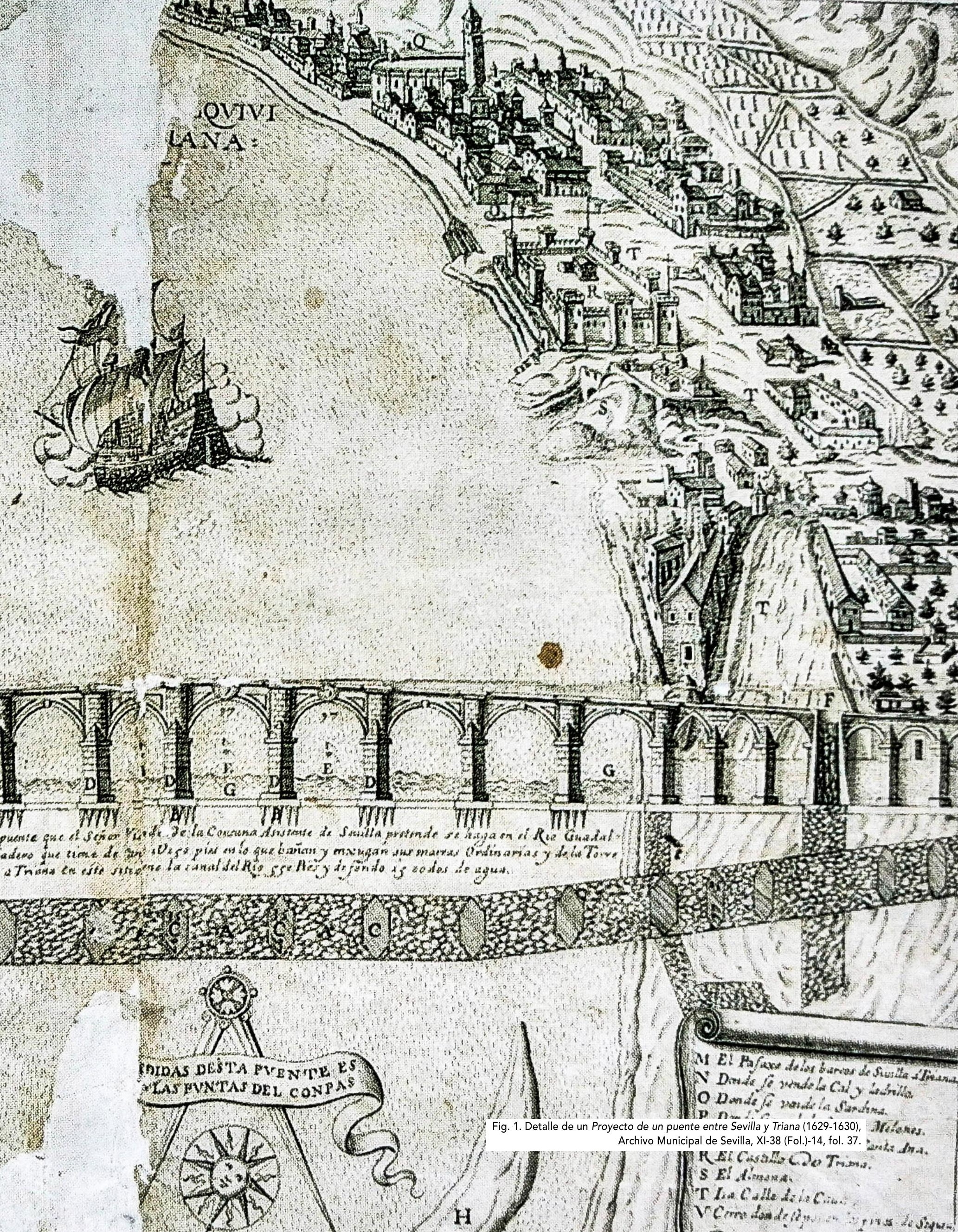




\section{Consideraciones sobre la sustitución del puente de barcas de Triana: un proyecto de puente de piedra (1631)}

Considerations on the replacement of the bridge of boats of Triana: a stone bridge project (1631)

\section{Marcos Pacheco Morales-Padrón}

Universidad de Sevilla, Espańa marcospachecomoralespadron@gmail.com https://orcid.org/0000-0001-9738-8870

\begin{abstract}
Resumen
El presente artículo intenta aportar nuevos datos sobre un interesante, como poco conocido, proyecto del siglo XVII para reemplazar al centenario puente de barcas de Triana. En las siguientes líneas trazaremos unas breves referencias biográficas sobre esta última infraestructura islámica, así como su aspecto o limitaciones, además de otros problemas que adolecía la estructura portuaria de Sevilla, que nos servirán como causa y contexto para enmarcar los futuros planes de construcción y financiación de la fracasada gran obra de sillería.
\end{abstract}

Palabras clave: Puente de barcas; Triana; Río Guadalquivir; Puerto de Sevilla.

\begin{abstract}
The present article tries to contribute new data on an interesting, as little known, seventeenth century project to replace the centennial bridge of boats of Triana. In the following lines we will draw a brief biographical references on this last Islamic infrastructure, as well as its aspect or limitations, as well as other problems that the port structure of Seville suffered, that will serve as cause and context to frame the future construction and financing plans of the unsuccessful great work of ashlar masonry.
\end{abstract}

Keywords: Boat bridge; Triana; Guadalquivir river; Port of Seville. 
En el siglo XVI, y gran parte del XVII, el Guadalquivir se erigió como la "columna vertebral de la ciudad hispalense y su cordón umbilical que la nutría con el resto del mundo", según el profesor Morales Padrón ${ }^{1}$. Fue el río una autentica vía internacional por donde los barcos subieron y bajaron, aunque, en muchas ocasiones, no pudieran atracar en el mismo Arenal ${ }^{2}$. Dentro de ese eje fluvial los surgideros más importantes -el piloto Escalante de Mendoza habla de ellos ${ }^{3}$ - eran Sanlúcar, Bonanza, Las Horcadas, El Borrego, El Puntal, Coria, San Juan de Aznalfarache y el muelle de Las Muelas o Camaroneros (Sevilla). No obstante, la zona portuaria básica quedaba comprendida entre la puerta de Triana y la Torre del Oro, aunque luego se amplió aguas abajo de esta última fortificación, donde actualmente se encuentra el palacio de San Telmo y paseo de Las Delicias, con protestas por parte de la Inquisición que alegaba derechos sobre dicho paraje $e^{4}$. El "Compás de las Naos" o Arenal, la zona portuaria eminente de la ciudad, no era suficiente para la concentración de flotas y convoyes ${ }^{5}$, por lo que en no pocas ocasiones los barcos se veían obligados a anclar en Coria o incluso mucho más abajo, en el ya mencionado sitio de Las Horcadas ${ }^{6}$.

El Arenal, espacio mal consolidado y embarrado comprendido entre las murallas del frente fluvial y la orilla opuesta a Triana ${ }^{7}$, comunicaba con la ciudad a través de dos puertas y postigos. Esta amplia explanada contaba con casetas y cobertizos para refugio de guardianes y mercancías, completando tales funciones de depósito las Atarazanas ${ }^{8}$ y unos almacenes que en 1590 el Ayuntamiento construyó en las cercanías de la puerta de Triana ${ }^{9}$. Junto a la Torre del Oro estaba el muelle de la Aduana ${ }^{10}$, mientras que en la orilla opuesta

1. MORALES PADRÓN, Francisco, Historia de Sevilla. La ciudad del Quinientos, Sevilla, Universidad de Sevilla (Colección de Bolsillo), 1989 , pág. 29.

2. El Arenal ha sido, desde la Edad Media hasta hace apenas 100 años, el lugar donde se aglutinaba el grueso de la actividad portuaria del Guadalquivir. En el siglo que nos interesa su nombre ya lo dice todo: se trataba de una yerma extensión arenosa, algunas veces polvorienta cuando no enfangada, donde tenían cabida todo tipo de géneros y labores relacionadas con la marinería, estiba/desestiba, tratos comerciales, almacenaje y reparaciones navales, entre otros muchos. Más información en DOMÍNGUEZ ORTíZ, Antonio, "La vida en los muelles del Arenal", CARRASCO, Diego (coord.), El río, el Bajo Guadalquivir, Sevilla, Equipo 28 (edición patrocinada por la Delegación de Cultura, Ayuntamiento de Sevilla, y la Consejería de Cultura y Política Territorial, Junta de Andalucía), 1985, págs. 43-47.

3. ESCALANTE DE MENDOZA, Juan, Itinerario de Navegación de los Mares y Tierras Occidentales. 1575, Madrid, Museo Naval, 1985, pág. 27 (Biblioteca Nacional de España, MSS/3104). Este manuscrito, terminado en 1575 y dedicado al rey Felipe II, es uno de los tratados de navegación y náutica más importantes y completos que se hayan escrito en el siglo XVI. La obra está dividida en 3 libros y escrito en forma de diálogos entre un joven que quiere conocer el arte de la náutica y el piloto del navío donde va embarcado. Mediante estas amenas conversaciones, Juan de Escalante detalladamente va describiendo los derroteros para ir de España a las Indias, a la vez que expone los conocimientos que se tenían en su época sobre astronomía, pilotaje, meteorología, cosmografía, cartografía, construcción naval, etc., todo ello enriquecido con sus experiencias.

4. Esta zona estaba ocupada por un arrabal escasamente poblado al que se salía por la puerta de Jerez. Mediante la bula del Papa Pio IV (1560) todo este terreno pasó a ser propiedad de la Inquisición de Sevilla (NAVARRO GARCÍA, Luis, "El Puerto de Sevilla a fines del siglo XVI", Archivo hispalense: Revista histórica, literaria y artística, $t^{\circ} 45,{ }^{\circ}{ }^{\circ} 139-140,1966$, pág. 8). Al año siguiente, 1561, Ortuño de Espinosa Briceño, secretario del Santo Oficio, se presentó ante el Cabildo para protestar por el daño que en estas tierras las estacas y barracas que los barcos clavaban para amarrar causaban en ellas (Archivo Municipal de Sevilla, a partir de ahora A.M.S., secc. X, $t^{\circ}$ 1, leg. 1, acta capitular del viernes 25 de enero de 1591). La ciudad, simple y llanamente, respondió que el uso de las naos de atracar allí era antiquísimo y que no podía ser estorbado (A.M.S., secc. $X, t^{\circ} 1$, leg. 2, acta capitular del miércoles 20 de febrero de 1591).

5. En una apreciación física, esta zona aproximadamente es un rectángulo de 300 varas de ancho por 900 de largo o lo que en medidas actuales es lo mismo, una distancia comprendida entre la Torre del Oro y el puente de barcas de $720 \mathrm{~m}$. Ello encerraba una extensión de 172.800 m². En lo que a superficie de flotación se refiere, si tomamos como ancho la longitud del citado puente $(200 \mathrm{~m})$, nos quedaríamos con 160.000 m2 de espacio para las maniobras navales (BABÍO WALL, Manuel, Aproximación etnográfica del puerto y río de Sevilla en el siglo XVI, Sevilla, Editorial Don Quijote, 1990, págs. 185-186).

6. En aquella época paraje marismeño sin hábitat humano o edificación alguna, a excepción de algunas chozas, ubicado entre las actuales localidades sevillanas de Los Palacios y Villafranca y Las Cabezas de San Juan.

7. Entre otras muchas obras, para más información recomendamos SERRERA CONTRERAS, Ramón María, Lope de Vega y el Arenal de Sevilla, Sevilla, Ayuntamiento de Sevilla y Real Academia Sevillana de Buenas Letras, 2007 o MONTOTO, Santiago, El Arenal de Sevilla en la historia y en la literatura: conferencia leída el día 16 de marzo de 1934 en el "Centro Cultural Tertulia del Arenal", Sevilla, Silverio Domínguez ed., 1934.

8. Sobre diversos aspectos históricos de las Atarazanas, consultar las recientes aportaciones científicas publicadas por el profesor Pablo Emilio Pérez-Mallaína Bueno.

9. A.M.S., secc. $X, t^{\circ} 1$, doc. 1 (actas capitulares del 20 y 24 de marzo de 1590).

10. Desde la década de 1430 hasta finales del siglo XVIII en el Arenal no existió más muelle que el situado junto a la Torre del Oro. Tenía unos 15 m de frente y estaba fabricado en madera. Según la documentación de la época, se le conocía como "muelle de la Yglesia" (sic) o de la "Fábrica", aunque más tarde también 
los puntos de atraque de Camaroneros ${ }^{11}$ y Las Muelas ${ }^{12}$. Los testimonios gráficos que conservamos de toda esta zona nos permiten recrear la estampa cotidiana de ella. Carpinteros de ribera desbrozando troncos, cordoneros en sus tareas, barcos varados que se calafatean, barberos que afeitan, jugadores, señoras que pasean a pie o en carrozas, cañones y maderos apilados junto al postigo del Carbón o de los Azacanes, frailes, recuas cargadas, soldados con sus arcabuces al hombro, artesanos, mercaderes, marinos, la "machina” o grúa de dos ruedas alzada junto al arroyo Tagarete ${ }^{13}$, los barqueros transportando pasajeros y productos, etc. Todos estos personajes integran un cuadro que mereció la atención de más de un pintor $^{14}$.

A partir del puente de barcas, que en las siguientes líneas trataremos con más detalle, se dilataba otro tramo que iba desde la puerta de Triana hasta la de Goles o Real, donde se extendía el barrio de los Humeros $^{15}$; habitado fundamentalmente por pescadores - calle Redes- al igual que las cercanas collaciones de la Magdalena y San Vicente. No faltaban por ninguna de estas partes los montones de basuras o muladares, fáciles de divisar en algunos testimonios gráficos conservados.

En la orilla derecha, frente por frente del Arenal, quedaría el arrabal de Triana con una población mayormente formada por hortelanos, gente de mar e industriales (alfares, bizcochos, jarcias, cerámica, pólvora, jabón, etc.). El puente y las barcas dependientes del municipio garantizaban la comunicación con este importante núcleo.

Igual que hoy, el río, el puente y el puerto ofrecían diversos problemas. En primer lugar, estaba el del dragado del fondo y la limpieza del mismo. El cauce del Guadalquivir no permanecía siempre expedito y en condiciones óptimas de navegabilidad a causa de la barra de Sanlúcar, los bancos de arena, las riadas o los barcos hundidos, que originaron una serie de puntos negros para el trayecto fluvial: Los Pilares (San Juan de Aznalfarache), Albayle (Coria), El Naranjal, Salmedina (Chipiona) o la propia desembocadura, entre otros muchos. Por estos motivos, la purga del cauce constituyó una perenne preocupación del municipio y de la Casa de la Contratación, con quien se discutía tal asunto. En 1578 el propio Felipe II expresaba la conveniencia de adecuar el cauce: "Yo he entendido que conuiene mucho limpiarse el rio de Seuilla, por que della a las

como de la "Aduana" o de "las dos ruedas" (RODRÍGUEZ ESTÉVEZ, Juan Clemente, Los canteros de la catedral de Sevilla: del Gótico al Renacimiento, Sevilla, Diputación Provincial de Sevilla, 1998, págs. 210 y 212).

11. Creemos que su situación estaba entre lo que hoy es el puente de San Telmo y el de Isabel II. De esta afirmación se parte de una forma indirecta y poco concreta por encontrarnos documentación referente a una zona donde se armaban, carenaban y calafateaban navíos. Sobre su curioso nombre, el cronista González de León cita textualmente "porque los que viven en él se dedican a la pesca de estos animalitos" (GONZÁLEZ DE LEON, Félix, Noticia artística, histórica y curiosa de todos los edificios públicos, sagrados y profanos de esta Muy Noble, Muy Leal, Muy Heroica e Invicta Ciudad de Sevilla, y de muchas casas particulares, Sevilla, Extramuros, 2008, pág. 48), siendo esta una opción que tampoco descartamos, aunque bien pudieran darse varias actividades a la vez.

12. Hay muchas referencias sobre dicha zona, pero no existe una localización concreta. Debía tratarse de un espacio solado, quizás con ruedas de molinos; de ahí su nombre. Creemos que era la orilla que hoy ocupan las instalaciones deportivas del Real Círculo de Labradores. El profesor Morales Padrón muestra sus reservas sobre esta ubicación y no le extrañaría que estuviese junto a la Torre del Oro, al lado del arroyo Tagarete, donde debieron de existir unas ruedas o muelas de molino (MORALES PADRÓN, Francisco, Sevilla y el Río, Sevilla, Servicio de Publicaciones del Ayuntamiento de Sevilla, 1980, pág. 27).

13. Sobre un sólido basamento de piedra de forma circular se erguía un mástil del que partía un brazo más o menos reforzado donde en su extremo se hallaba un juego de poleas. Esta estructura fue concebida para trasladar mercancías del barco al muelle o viceversa, y hallaba su elemento más característico en una gran rueda de madera. Era accionada por un operario que caminaba en su interior, proporcionando la fuerza para elevar los materiales (como curiosidad, en el Centro de Interpretación de la Autoridad Portuaria de Sevilla existe una réplica casi a tamaño natural). Llama la atención que, de una manera muy simple, pero con su particular fisonomía, nuestra machina aparece representada en el bello pergamino de la Real Cedula de 1549 (GARCÍA FUENTES, Lutgardo y NAVARRO GARCÍA, Luis, Sevilla entre dos mundos, Sevilla, Algaida, 1992, pág. 10).

14. Entre los grabados lo detectamos en el de Georg Braun y Frans Hogenberg recogido en su famosísimo Civitatis Orbis Terrarum (1572) y en el de Ambrosius Brambilla (1585). De las obras pictóricas a señalar la ya estudiaba Vista de Sevilla (entre 1576-1600) atribuida a Alonso Sánchez Coello y Puerto de Sevilla (siglo XVII), anónimo, de la Hispanic Society of America (Nueva York).

15. Más información en DEL POZO Y BARAJAS, Alfonso, Arrabales de Sevilla: morfogénesis y transformación. El arrabal de los Humeros, Sevilla, Universidad de Sevilla, 1996 
Horcadas dizen que se ha hecho innauegable para nauios con los baxios que tiene, y por otras muchas causas bien sera que si ay algo en Consejo, que toca a esto se vea" ${ }^{16}$. Dos años más tarde se concertaba con Antonio de Cibori la extracción de seis naves hundidas que obstaculizaban la navegación ${ }^{17}$; diez después el veneciano Pascual de Montana presentaba un ingenio para limpiar el fondo del Guadalquivir ${ }^{18}$. Son ejemplos aislados de un latente e incesante celo del consistorio hispalense sabedor de lo que esta vía de comunicación significaba. Al río también le afectaba la extracción del barro en la dehesa de Tablada por la erosión que en las márgenes provocaba, y por eso las autoridades municipales lucharon contra los barreros y olleros de Triana, aunque sin lograr resultados definitivos ${ }^{19}$.

El aumento del arqueo de los navíos -ya en 1570 hay algunos de 1.000 toneladas- también planteó dificultades. Barcos de gran porte debían ser remolcados por galeras, o se imponía el empleo de embarcaciones de alijo que acarreaban río arriba lo que las naves de gran volumen traían, pero que por su calado ellas mismas no podían depositar en el Arenal.

Igualmente, grave era la imposibilidad de calafetear los barcos con comodidad y garantías de seguridad en la propia ciudad, aunque tampoco había lugares apropiados ni los sistemas conocidos eran totalmente eficaces. El molusco de la broma, Teredo Navalis, afectaba a las maderas de los buques convirtiéndolos en auténticas cribas; para proteger los cascos se ideó el sistema del emplome de la obra viva. Una vez en Sevilla, los barcos provenientes de su periplo atlántico debían sufrir carenas y era entonces cuando no se contaba con lugares idóneos ni con sistemas eficaces. Debido a este menester, se solían conducir hasta San Juan de Aznalfarache o a La Puebla Vieja; allí se les varaba o "sacaba al monte", aunque otras veces se les hacía flotar a base de colocarles en sus bandas pipas o toneles, cuando no se les acostaba sobre otro barco hasta que las quillas quedaran al aire ${ }^{20}$.

Finalmente, la aspiración de llevar la navegabilidad del río hasta Córdoba, como en la antigüedad, también constituyó una obsesión de la ciudad de Sevilla ayudada por el famoso maestro Fernán Pérez de Oliva. En 1524 este humanista e ingeniero incitó al cabildo cordobés para que acometiera las obras necesarias para prolongar la llegada de riquezas de las Indias vía fluvial hasta el puente romano ${ }^{21}$. Más de una vez se intentó establecer la conexión con la vecina ciudad, consciente el Cabildo que ello facilitaría el ingreso en Sevilla de abastecimientos siempre necesarios. En 1525 Carlos I llegó a ordenar la reunión de representantes de ambas poblaciones, juntamente con técnicos, para estudiar tal posibilidad y redactar un presupuesto de obras. El mandato del Emperador nacía de una petición elevada por los procuradores en cortes de Sevilla y Córdoba $^{22}$, pero solo quedó en eso: un proyecto. En 1561 se forjó otro nuevo intento interviniendo el matemático Ambrosio Mariano y algunos ingenieros, pero tampoco el problema encontró solución ${ }^{23}$.

16. Archivo General de Indias (a partir de ahora A.G.I.), Indiferente General, leg. 739, doc. 79 (consulta del Consejo de Indias, Madrid, 17 de mayo de 1578).

17. A.M.S., Papeles Importantes, $t^{\circ}$ XII, docs. 7, 8 y 9 (carta de la ciudad de Sevilla a Antonio de Cibori, autorizándole a sacar del río seis naos que están anegadas y todo el lastre... pagándole por cada una 2.000 ducados, y concediéndole por veinte años el monopolio de su invento, Sevilla, 13 de mayo de 1580).

18. A.G.I., Indiferente General, leg. 789, doc. 79.

19. NAVARRO GARCÍA, Luis, "El Puerto de Sevilla...", op. cit., págs. 20-26.

20. En 1560 a Jácome de Francisco se le concedió el privilegio de aplicar cierto secreto o nueva técnica para carenar navíos en el río de Sevilla (Museo Naval de Madrid, Col. Navarrete, $t^{\circ}$ XXII, doc. 21).

21. RUíZ PÉREZ, Pedro, El "Razonamiento de la navegación del Guadalquivir" de Fernán Pérez de Oliva, Córdoba, Ediciones La Posada, 1988.

22. A.M.S., secc. I, carp. V, doc. 78 (Real Provisión, Toledo, agosto de 1525).

23. Más información en LAGUNA RAMíREZ, María Concepción, El Guadalquivir y Córdoba en el Antiguo Régimen: navegación, conflictos sociales e infraestructura económica, Córdoba, Universidad de Córdoba, 1997. 


\section{proyecto de sustitución del puente de barcas}

La relación histórica de Sevilla con el río ha sido una constante que llega hasta nuestros días. Sin embargo, el papel de algunos de los agentes más importantes de este maridaje, como son los puentes sobre el Guadalquivir, permanece vagamente sin estudiar. Este tipo de infraestructuras fueron creadas por y para la ciudad y, a su vez, concebidas para el uso de la población o su puerto. Hay casos en los cuales dichas obras se levantan para reafirmar la capacidad constructiva de una ciudad, pueblo o nación, y Sevilla, como veremos, ha sido uno de esos casos. Son piezas fundamentales de nuestro patrimonio no solo por su belleza, perdurabilidad, materiales o hechos significativos vividos, sino porque también forman, o han formado, parte de nuestra historia.

El primero que se tendió entre ambas orillas fue el trianero puente de barcas. Durante casi siete siglos (1171-1852), fue testigo de un periodo muy amplio y repleto de acontecimientos históricos básicos, comenzando por el esplendor de la ciudad durante imperio almohade (1147-1248) y terminando con la época isabelina (1833-1852). En los textos medievales del cronista andalusí Ibn Sāhib al-Salāt se cita que:

"Comenzaron los arquitectos y obreros su construcción y los trabajos de carpintería e ingeniería para colocarlo sobre el río el sábado, primero de Muhárram del año 567 (4 de septiembre de 1171), y se completó el 7 de Safar del mismo año 567 (9 de octubre), fecha en la que se amarró el pasadizo sobre el puente de barcas y se colocó sobre el río. Fue un día solemne por el redoble de los tambores, la presencia de los escuadrones de los soldados y el despliegue de las banderas y estandartes" ${ }^{24}$.

En cuanto a su ubicación, se encontraba en la actual posición de su sustituto: el puente de Isabel II. El sistema era análogo al de un pantalán, es decir, una serie de naves, trece citan algunos autores ${ }^{25}$, amarradas entre sí por gruesas cadenas que con tablones sobre sus cascos formaban un paso "estable" de 149 metros de longitud. No obstante, la configuración del mismo no siempre fue la misma. En el siglo XVIII el historiador Fermín Arana de Varflora nos aporta más detalles:

"Para franquear el paso de la ciudad al barrio de Triana hai un puente de madera sobre diez barcos chatos (antiguamente fueron once) y aunque algunos quisieran fuera su piso más suave, debe reflexar que en su construcción se ha mirado asi a la robustez como a la comodidad de caidas e incomodidades. Están los barcos asegurados entre si con fuertes maderos y asidos al fondo del rio con grandes anclas sostenidas de gruesos cables. Corren gruesas cadenas de hierro y cabos que asegurados en las márgenes hacen el puente poderoso para resistir los continuos fluxos y refluxos de las aguas"26.

El acceso al mismo, desde la ciudad, se realizaba a través de una calzada empinada que nacía en la puerta de Triana y que tenía unos arcos u ojos con el fin de permitir el paso de las aguas durante las crecidas. Esta entrada, una vez atravesado el puente, terminaba en el altozano, junto al castillo de la Inquisición, en una de cuyas torres había un gancho para amarrar los pontones. Por el lado de Sevilla, entre el río y la calle Cantarranas, quedaba un espacio ancho defendido por un paredón.

24. AL-SALAT, Ibn Sahib, Textos Medievales 24. Al-Mann Bil-Imáma, Valencia, Anubar Ediciones, 1964, págs. 64-65 y 187.

25. PÉREZ AGUILAR, Francisco, El puente de barcas de Sevilla (1171-1852) y puentes de barcas de Sevilla y Cádiz, Sevilla, Los Libros de Umsaloua, 2014 , pág. 37.

26. ARANA VARFLORA, Fermín, Compendio histórico descriptivo de la muy noble y muy leal ciudad de Sevilla metrópoli de Andalucía, Sevilla, Editorial Maxtor Librería, 2008, pág. 93. 
A pesar de la existencia de esta infraestructura, uno de los problemas crónicos que siempre adoleció la ciudad fue la dificultad de disponer de un paso seguro sobre el Guadalquivir. Hasta que en 1852 el puente de Isabel II solventó este asunto ${ }^{27}$, desde la inauguración del puente de barcas ${ }^{28}$ no se construyó ninguno otro. Es decir, en 681 años tan solo existió esta insuficiente plataforma, cuyas continuas reparaciones, unidas a las crecidas del río que lo arruinaban, entorpecían de sobremanera el tráfico terrestre. Sorprende ver como una ciudad tan rica y populosa como era la Sevilla "del Quinientos", en palabras Morales Padrón, no tuviera un puente de piedra acorde con su importancia como ya lo tenían otras como Córdoba, Toledo o Mérida.

Pero, ¿por qué esta infraestructura islámica tuvo tan dilatada vida operativa? En relación a ello, resulta interesante insertar un extracto de la carta enviada por don Diego Hurtado de Mendoza, vizconde de la Corzana y asistente de la ciudad (1629-34), a don Gaspar de Guzmán, conde-duque de Olivares donde dice: "como siendo tan osado y valiente el cielo desta opulentissima Ciudad de Sevilla, desde su fundación hasta oy, no an sus antiguos ni modernos intentado la puente de piedra: como se las han puesto en Europa a los mayores rios della en sus provincias, en Londres al Támesis, en París a la Garona, en Alemania al Danubio, en Roma al Tíber, en España al Tajo, y al Duero; y sobre ellos al estrecho que divide la Isla de Cádiz de la tierra firme, que buelve a juntar la puente de Zuaço?'29.

La respuesta básicamente tenemos que encontrarla en la técnica de aquella época. A pesar de la imperiosa necesidad que había, los avances humanos no daban de sí para levantar un gran puente de piedra en esta zona. El lecho fluvial inestable y limoso, sumado a la fuerte corriente que en el meandro de Triana el río adquiría, impedía una construcción de tal envergadura. De esta manera, durante casi 7 siglos el puente de barcas suplió esta carencia junto con una flotilla de lanchas toldadas ${ }^{30}$ que iban y venían de una orilla a otra ${ }^{31}$. Posiblemente, estos problemas de cimentación sobre el Guadalquivir fueron la causa de que los romanos eludieran la construcción de un puente fijo en la entonces Híspalis o de que los árabes eligieran un tipo de puente articulado, más flexible y dúctil a las corrientes del río, además de por evidentes razones económicas.

Como decíamos, el principal problema del puente de barcas era su costoso mantenimiento, que corría a cargo de quien arrendase su explotación (tenedores). Las inclemencias del tiempo, riadas y los mismos barcos que solían amarrarse a él, pese a estar prohibido, exigían continuos arreglos y la importación de maderas procedentes de los bosques de Constantina ${ }^{32}$. No era raro que dichos tenedores se quejaran y pidieran ayuda al Cabildo cuando los daños eran de consideración ${ }^{33}$. Por ejemplo, en una inesperada inundación las simples balsas cargadas de cañas o maderos que arremetían contra las barcas podían acabar rompiendo la trabazón de cáńamo, por lo que ante estas eventualidades invernales se optaba por cortar el tablero del puente ${ }^{34}$.

27. Véase LEFLER PINO, Joaquín, "El puente de Triana (1 parte)", ALONSO FRANCO, Eugenio (coord.), Los puentes sobre el Guadalquivir en Sevilla, Sevilla, Colegio de Ingenieros de Caminos, Canales y Puertos, 1999, págs. 39-51.

28. Se inauguró tras solo un mes de trabajo. Los primeros en atravesarlo fueron tropas islámicas con objeto de socorrer a la plaza de Badajoz llevando trigo, cebada, víveres diversos y pertrechos de guerra.

29. Real Academia de la Historia (Madrid), a partir de ahora R.A.H., 9/3691 (117) (a Don Gaspar de Guzmán, Conde de Olivares, Duque de Sanlúcar la mayor, Marques de Heliche... Capitán general de la... Sevilla... 2 de septiembre de 1631).

30. Sobre la tipología de estas consultar AZNAR VALLEJO, Eduardo, "Barcos y barqueros en Sevilla", Historia. Instituciones. Documentos, n. ${ }^{\circ} 21,1994$, págs. 1-12.

31. "cuyo passaje le cuesta al pueblo mucha suma de ducados, con grandes descomodidades y peligros". R.A.H., 9/3691 (117).

32. A.M.S., secc. III, $t^{\circ} \mathrm{XIII}$, leg. 31 (solicitud en 1570 de Juan Antón, pidiendo el pago de las maderas que hizo traer por comisión de Dr. Liébana, Teniente de Asistente...).

33. A.M.S., sección IV, tomo XXIX, doc. 61 (memorial de Gregorio Núñez Salguero, a cuyo cargo estaba el reparo del puente en 1684, pidiendo una ayuda de costa por las considerables pérdidas que había tenido en el referido año).

34. A.M.S., sección III, tomo XIII, doc. 29 (memorial de Francisco de Valverde, asentista del puente de barcas entre Sevilla y Triana, manifestado el destrozo de 
Don Diego Hurtado de Mendoza nos recuerda sobre su mal estado que:

"muchos dias del año esta esta puente de barcas, ya con necesidad de quitarle una barca y poner otra, ya la tablaçon de la puente tan desigual, o desportillada, que ocassiona muchas caydas, con riesgo de los bagajes, $y$ daño de las mercaderías que llevan, ya sin pretiles, y con riesgo de que son muchos los que de noche se caen en el río, de que no queda traslado ni noticia, que por las continuas crecientes del invierno están las entradas de la puente tomadas de el agua'35.

Las posteriores obras de reparación tras una riada podían ocupar hasta tres meses, tiempo durante el cual la actividad económica mermaba considerablemente debido a la incomunicación de ambas orillas. La definitiva solución a dicho problema estaba en un puente de piedra. El más grave obstáculo a su construcción radicaba en la carestía de la propia obra, a lo que habría de añadir la insolvencia municipal y las consideraciones técnicas, sobre todo la mala calidad del lecho del río, que obligaba a profundizar hasta encontrar el estado idóneo para poder cimentar los pilares ${ }^{36}$. Sin embargo, el cabildo estaba dispuesto a aventurarse en la empresa si tenía la "certidumbre de que las demás ciudades y lugares del reino an de ayudar, al igual que Sevilla

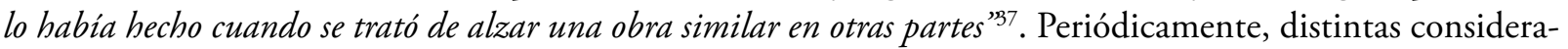
ciones tomaban protagonismo en relación con el puente, especialmente las de orden económico, ya que los 3.600 ducados que la ciudad abonaba a los tenedores suponían un gasto excesivo para las arcas de la misma ${ }^{38}$. Igualmente, el desabastecimiento que la ciudad sufría a consecuencia de las continuas roturas y los daños que los cascos de las naos surtas en el Arenal producían al chocar con los pontones ${ }^{39}$, llevaron al municipio a estudiar posibles soluciones, contemplándose seriamente la posibilidad de construir un nuevo puente.

Francisco de Arińo, cronista de la ciudad y vecino del Altozano, hace una detallada referencia a uno de los muchos sucesos que acontecieron en el puente como consecuencia de los avatares de la climatología: "El miércoles 22 de junio de 1594 entre las tres y las cuatro de la tarde, vino tan gran tempestad de aire y polvareda, que no se veían unos a otros y no quedó en el río nao, fragata, chalupa, carabela, barcos ni barquillos que por amarrados que estuviesen no rompiesen las amarras y se encontrasen unos con otros, y un carabelón vino sobre la puente con tal pujanza, que embistió con ella y se rompió por ambas compuertas y la llevó toda junta el aire y carabelón hasta la almona de Triana y fueron encima de ellas dos hombres $y$ una mujer echados y agarrados de los cabiroles de ellas y un buey, y dentro de la casa de la puente el que pide para las almas del purgatorio y Domingo Pérez, guarda de la puente, dentro de un barco que lo estaba achicando el agua que tenía; al tiempo que la puente rompió iba a pasar un hombre en un caballo castaño

cables y barcos originado en la avenida del río por una balsa de 3 a 4.000 haces de cañas, y pidiendo resto de su salario para atender a reparar el siniestro). Otro ejemplo ocurrió el 5 de enero de 1435, cuando los guardas del puente de barcas tuvieron que cortar las amarras que aún quedaban sin arrancar debido a una fuerte crecida del Guadalquivir. La infraestructura, en su deriva, chocó contra el mástil de una nave hundida, girando sobre él su extremo de Triana hacia el barrio de la Carretería, rompiéndolo, lo que lo liberó hasta que una vieja galera lo paró a la altura de las Atarazanas, siendo posteriormente amarrado. Días después fue remolcado, reparado y vuelto a poner en servicio (PÉREZ AGUILAR, Francisco, El puente de barcas..., op. cit., pág. 41).

35. R.A.H., 9/3691 (117).

36. Lo que solo pudo hacerse en 1845, durante el desarrollo del puente de Isabel II o de Triana, pues antes la técnica no se encontraba tan avanzada. En GRACIANI GARCÍA, Amparo, "La construcción del Puente de Isabel II de Sevilla. Los problemas de cimentación", Actas del Primer Congreso Nacional de Historia de la Construcción, Madrid, 19-21 septiembre 1996, Madrid, I. Juan de Herrera, CEHOPU, 1996, págs. 265-269.

37. A.M.S., Escribanía de Cabildo, sección III, tomo XIII, doc. 32 (carta para Domingo de Saavedra, veinticuatro de Sevilla, y comisario Diego Núñez Pérez, procurador veinticuatro della. 6 de noviembre de 1586).

38. PÉREZ AGUILAR, Francisco, El puente de barcas..., op. cit., pág. 67.

39. El 22 de junio de 1594 una tempestad hizo romper las amarras de una gran carabela que embistió al puente de barcas rompiéndolo y provocando la muerte de varias personas. Mientras dicho paso permaneció en reparaciones, los barqueros aprovecharon la coyuntura incrementando sus tarifas por cruzar a la gente y sus animales de una a otra orilla (DE ARIÑO, Francisco, Sucesos de Sevilla de 1592 a 1604, Sevilla, Colegio Oficial de Aparejadores y Arquitectos Técnicos de Sevilla, 2005, pág. 18). 
y cayó el caballo al río y salió por las escaleras del castillo y el hombre cayó por las ancas del caballo en el suelo del Altozano. Y no quedó en Sevilla y Triana hombre ni mujer que no viniese a ver la puente sobre la almona, y el jueves 23 de junio a medio día pasó gente por la puente ${ }^{{ }^{\prime 4} 0}$.

Como remedio, en 1586 el Cabildo estableció contactos para solicitar del rey Felipe II la licencia necesaria para levantar un puente de piedra a la altura de lo que hoy es El Barranco-Chapina. Entre 1563 y 1587 a las consideraciones municipales fueron presentados 6 proyectos diferentes ${ }^{41}$, siendo los más importantes los siguientes: Fabricio Mondente con la idea basada en un puente de madera y hierro, para cuyo estudio el Consejo creó una comisión y mandó realizar una maqueta, y en 1578 el del conde de Barajas, futuro asistente de la ciudad ${ }^{42}$. A pesar del empeño puesto por las autoridades hispalenses, el proyecto acabó postergándose por 43 años.

Los planos volverían a rescatarse en 1629 tras el desastroso "año del diluvio" que azotó Sevilla en $1626^{43}$ que, según el cronista Diego Ortiz de Zúníga, costó 4.000.000 de ducados. Fue tal la magnitud de la catástrofe que las aguas cubrieron un tercio de la ciudad y, como consecuencia, 3.000 casas quedaron entre maltrechas y destruidas ${ }^{44}$. Viendo que las comunicaciones nuevamente quedaban rotas y que los problemas ligados al Guadalquivir iban a más, don Diego Hurtado de Mendoza, en calidad de asistente de la ciudad (1629-34), hizo el intento que más posibilidades tuvo de levantar un puente de piedra. A iniciativa suya le pidió al conde-duque de Olivares apoyo en la Corte para llevar a buen puerto la obra. Con la colaboración de Andrés de Oviedo, maestro mayor de obras del Consejo, se trazó la planta y montea de la infraestructura proyectándose también su entorno ${ }^{45}$. En un primer momento se pensó construirlo en la zona conocida como el "Bañadero", unos 100 metros aguas arriba del puente de barcas, donde el río tenía menor profundidad, aunque era más ancho (1.150 pies por solo 550 a la altura de la Torre del Oro ${ }^{46}$ ). Dos siglos después los espontáneos baños en el río que en Torneo y los Humeros se daban corroborarían tal curioso nombre de ribera ${ }^{47}$.

Este mismo personaje aseguraba la idoneidad del suelo de la zona propuesta ya que: "aviendole lançado buços a reconocelle la profundidad, an sacado la greda en que vieron los ferros y ancoras de los navios, tan fixamente amarrados como silo estuvieran a una peña". Corroboraban la firmeza del lecho las murallas de la ciudad que lindaban con la orilla, puesto que "ni el tiempo, ni los combates de Marte, ni la falta del cimiento fixo ayan hecho en ellos señal de mengua, que acuse de flaqueza al terreno sobre que se levantaron dentro del agua". Sobre las corrientes, "cuyo ruydolo, violento y rápido corriente, impide las maquinas necesarias, derribando y arrasándolo todo", contestaba que en esta parte del río "satisfará el silencio de la mana corriente de Guadalquivir". Como decíamos, otro factor determinante para la elección de dicho lugar fue la poca profundidad, pues "no passa su medida en la parte más honda, de tres estadios". No obstante, advertía que "quanto mas ocuparen

\footnotetext{
40. Ibídem, págs. 18-21.

41. Puede consultarse el de don Gonzalo de Saavedra y Pedro de Andrada en A.M.S., sección III, tomo XIII, doc. 33.

42. Ibídem.

43. GONZÁLEZ DE CALDAS, Victoria, "Arriadas en Sevilla", CARRASCO, Diego (coord.), El río, el Bajo..., op. cit., págs. 54-61.

44. ORTIZ DE ZUÑIGA, Diego (Ilustrados y corregidos por Antonio María Espinosa y Carzel), Anales eclesiásticos y seculares de la muy noble y muy leal ciudad de Sevilla, metrópoli de Andalucía, Sevilla, Guadalquivir, 1988, pág. 214.

45. Puede consultarse en CABRA LOREDO, María Dolores (con la colaboración Elena María Santiago Pérez), Iconografía de Sevilla, Tomo primero, 1400-1650, Sevilla, FOCUS (Fundación Fondo de Cultura de Sevilla), 1988, págs. 160-166.

46. A.M.S., sección IV, tomo XXIX, doc. 57 (informe dado por Juan Bautista barios en 1635, de la obra que necesitaba el puente de Triana).

47. SANCHÍS RAMÍREZ, José Pascual, "La natación higiénica en el río Guadalquivir en el siglo XIX", Espacio y Tiempo: Revista de Ciencias Humanas, n. 22,2008 , págs. 233-246.
} 
los pilastrones de la puente de piedra la madre del río, tanto más à de çoçobrar el agua de sus crecientes, y salir de madre, inundando los arrabales de Sevilla en riesgo de la ciudad’48.

El gran puente planeado era de sillería almohadillada con más de 25 arcos, unos apuntados y otros, los que cruzaban el cauce, semicirculares. Las enjutas de estos últimos se ornamentaban con motivos estéticos del bajo Renacimiento. Tenía fuertes estribos para cortar las crecidas del Guadalquivir, con tajamares y dos rampas de acceso por la margen de Triana. Para que se hagan una idea de sus dimensiones, el puente romano de Córdoba tiene 16 arcos que suman 331 metros, mientras que el sevillano hubiera sido uno de casi 450 metros de largo.

Para el abastecimiento de materiales el asistente recordaba en la carta la cercanía de las canteras de Alcalá del Río para "toda la que es necessaria y conveniente para debaxo del agua", mientras que para la obra muerta se disponía de las de Utrera y Espera, además de las de Santiago de Jerez, "de adonde por el río a muy poca costa, puede traer quanta huviere menester". La madera para las cajas de los pilastrones fácilmente se podía adquirir de las riberas, con lo que se excusaba "mucha parte de la costa desde fabrica". Por otro lado, en lo que al apartado de la financiación se refiere, se redactó un presupuesto con el fin de recaudar los 50.000 ducados que se suponía tendría de coste:

- Cada bestia pagaría de portazgo 2 maravedíes, pero 3/4 el carro cargado.

- 1 real cada 100 carneros y 8 cada 100 machos.

- 2 maravedíes por cada res vacuna.

- 1 real al mes en cada taberna, bodegón y pastelería de la ciudad.

- Gravar con 8 maravedíes cada arroba de vino "de las que entran en Sevilla para su gasto".

- "Otro real cada mes a los alojeros los seis meses del verano".

- Los 12.000 ducados que se cobraban de la entrada del pescado para las fortificaciones de Cádiz, ya terminadas, se aplicarían a la obra del puente.

- La lonja de los mercaderes prestaría los 4.000 ducados restantes.

Además, a la larga la ciudad se ahorraría los 6.000 ducados que le costaba el constante mantenimiento del puente de barcas.

Resulta sumamente curioso que el Cabildo pretendiera construir sobre los pilastrones del nuevo puente hasta 60 casas, a la manera del florentino Ponte Vecchio, "que cada una dellas tendrá treinta pies de frente, importarán cada año el alquiler de estas casas a la ciudad, quatro mil ducados"; toda una ayuda con la que poco a poco se podría ir pagando el empréstito de la Lonja. Una vez abonado éste, Sevilla se hallaría "con la puente que oy no tiene, y con más de diez mil ducados de renta perpetuos para sus propios ${ }^{349}$ fruto de los alquileres y de no tener que destinar continuos fondos para la reparación del pontón islámico. Aparte de este plan de financiación, las autoridades municipales confiaban en que "siendo tan necessaria esta obra" el Consejo de Castilla concedería un repartimiento de 56.000 ducados cada año. Esta cantidad iría destinada en verano para "labrar maderas para las cajas de los pilastrones: y assi mismo en las canteras referidas sacar la piedra necessaria, para en llegando el principio del verano fixar las cajas referidas, como conviene, y en estándolo, y agotada el agua

48. R.A.H., 9/3691 (117)

49. R.A.H., $9 / 3691$ (117) 
de dentro dellas, yr cimentando y levantando en cada verano uno de los tres mayores pilastrones, porque los demás se pueden hazer más fácil y brevemente, por los insignes artifices destos tiempos" $"$.

Finalmente, el 2 de septiembre de 1631 el vizconde de la Corzana envió al conde-duque de Olivares una carta con el boceto del puente; impreso por Francisco Lyra ${ }^{51}$. El proyecto, aunque resolvía los problemas técnicos (poca profundidad del cauce, corrientes suaves y cimentación adecuada), fue rechazado por Madrid. Lo impopular de sufragar la obra con impuestos grabando las mercancías de consumo, dejaba a la ciudad con su antiguo puente de barcas que 37 años después, en 1671, ¡cumpliría los 500 años!

La necesidad de una nueva infraestructura de este tipo era incuestionable ya que, por aquel entonces, unas 3.000 cabalgaduras eran las que a diario pasaban por el puente ${ }^{52}$. Como curiosidad, la desigualdad de las tablazones daba origen a múltiples riesgos para las personas, mercaderías y bestias, pues eran muchos los que caían al río durante la noche ${ }^{53}$. Pese a este análisis negativo, el Cabildo no perdió la esperanza y para el siglo XVIII conocemos la existencia de otro proyecto para llevar a cabo "la construcción de un puente de material". Los autores fueron Ginés y Pedro de San Martín, ambos maestros mayores de la ciudad. No obstante, sus ideas nuevamente no llegaron a cuajar ${ }^{54}$.

\section{Conclusiones}

Sevilla no abandonaría la idea de unir ambas orillas a través de un puente hecho y derecho; nunca mejor dicho. Con la nueva era industrial que se abría en el siglo XIX, el hierro se convirtió en el perfecto sustituto de la madera. Las propuestas siguieron sucediéndose hasta que en 1844 los ingenieros franceses Gustavo Steinacher y Ferdinand Bernadet presentaron 3 diseńos: uno de piedra, otro colgante y uno de hierro colado con dos pilastras centrales. Finalmente, este último resultó ser el elegido para materializar el futuro puente de Isabel II. Después de 7 años de obras, el 21 de febrero de 1852 se inaugurós5 ${ }^{5}$, con ello, el arrabal de Triana por fin se convirtió en barrio, que a partir de entonces aparecerá fielmente unido al casco histórico sin temor a permanecer incomunicada en momentos de riadas.

Pobre de su sustituto, el puente de barcas, que acabó sus días siendo vendido en subasta como leña ${ }^{56}$.

\footnotetext{
50. Ibídem.

51. Dicha epístola, con las medidas ya descritas, puede consultarse en MORALES PADRÓN, Francisco, Memorias de Sevilla: (1600-1678), Sevilla, Publicaciones del Monte de Piedad y Caja de Ahorros de Córdoba (Colección Mayor), 1981, págs. 202-207.

52. PÉREZ AGUILAR, Francisco, El puente de barcas..., op. cit., pág. 72.

53. Por ejemplo, según Francisco de Ariño el 14 de octubre de 1595 "a las ocho y media de la mañana pasando una manada de puercos de Montero por la puente y hicieron un remolino en ella y se hundieron dos barcas de ella y se quebró y cayeron en el río muchos de ellos y fue Gonzalo Eslava, alquacil de Triana con Damián Pérez Escribano y Montero por las carabelas de las sardinas y sacaron muchos que tenían usurpados, y la ciudad mandó a aderezar la puente a costa de Montero y poner barcas para pasar gente y bestias, y el 18 de octubre a las diez del día la aderezaron y les dio Montero un gran almuerzo a los carpinteros. Costole la burla de la gente prieta 328 ducados" (DE ARIÑO, Francisco, Sucesos de..., op. cit., págs. 18-21). Más luctuoso fue el accidente ocurrido el 14 de junio de 1850. En aquel día don Pedro de Montes, escribano mayor del juzgado de la capitanía general, y algunos amigos realizaron una excursión a la Cartuja junto a sus esposas. Las damas y las hijas del señor Montes iban en una tartana que por la tarde cruzaba el puente de barcas hacia Triana, pero debido al estiaje del río, el paso de madera del pontón se encontraba más bajo de lo habitual y consecuentemente la pendiente del tramo final del puente antes de la entrada en el extremo de Triana era más acentuada. La calesa, de gran peso, cedió hacia atrás quebrando uno de los tirantes de la cabalgadura. En ese movimiento rompió la barandilla de madera precipitándose al agua falleciendo dos hijas del señor Montes (PÉREZ AGUILAR, Francisco, El puente de barcas..., op. cit., págs. 159-160). 54. Ibídem.

55. LEFLER PINO, Joaquín, “El puente de Triana (1 parte)", ALONSO FRANCO, Eugenio (coord.), Los puentes sobre..., op. cit., págs. 48-49.

56. Sobre dicha subaste puede el proceso en A.M.S., sección XX, caja 592, doc. 4.852
} 


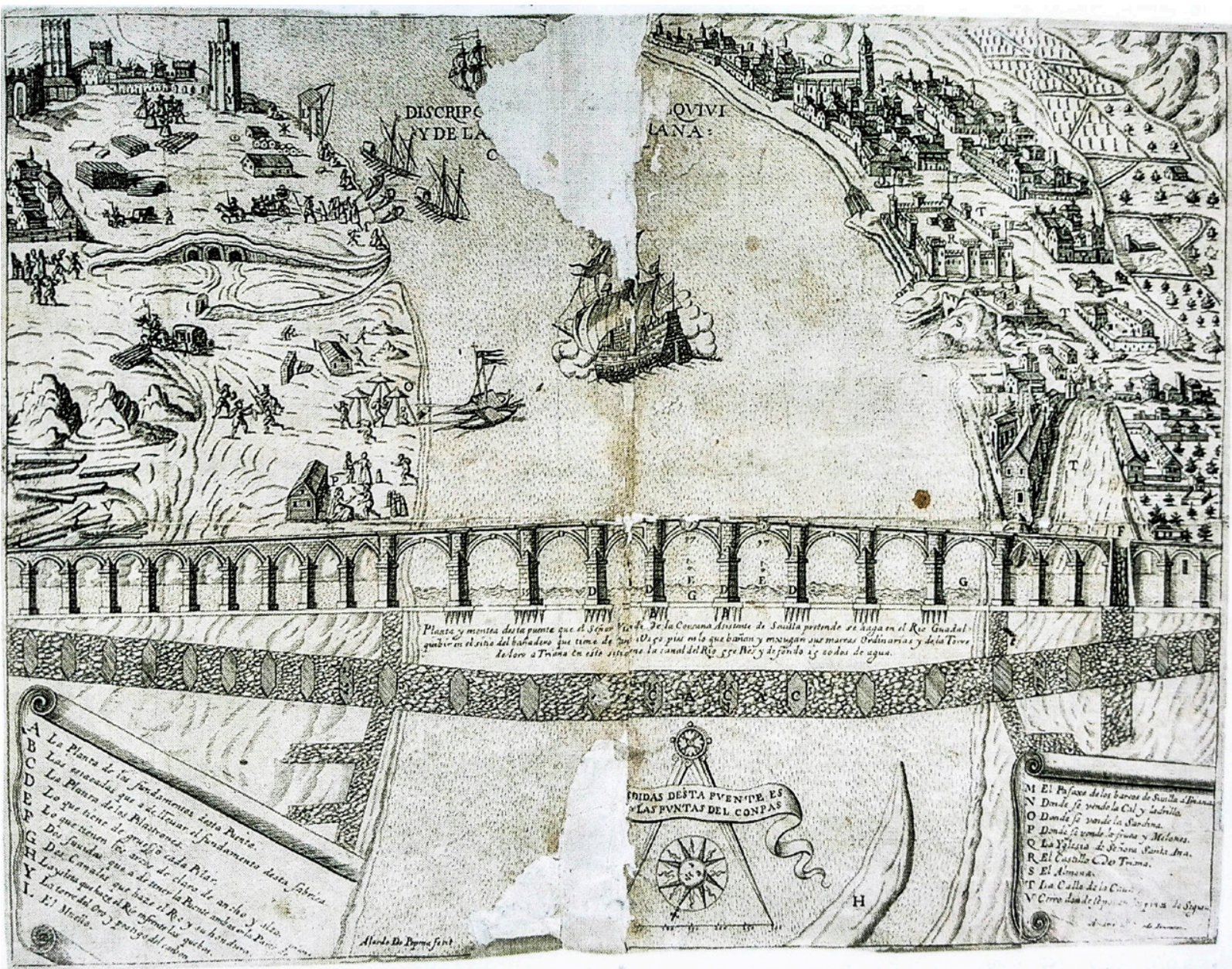

Fig. 1. Proyecto de un puente entre Sevilla y Triana (1629-1630), Archivo Municipal de Sevilla, XI-38 (Fol.)-14, fol. 37.

Apéndice documental

Título Proyecto de un puente entre Sevilla y Triana (Fig. 1)

\section{Fecha}

Autor/es

\section{Leyenda y transcripción}

Arriba al centro: DESCRIPCION DEL RIO GUADALQUIVI Y DE LARENAL DE SEVILLA Y TRIANA CON SU BEGA.

En el centro, debajo del puente: Planta y montea desta puente que el Señor Visconde de la Corsana Asistente de Sevilla pretende se haga en el Rio Guadalquivir en el sitio bañadero que tiene de ancho 1150 pies en lo que bañan y enxugan sus mareas Ordinarias y de la Torre de loro a Triana en este sitio tiene la canal del Rio 550 Pies $y$ de fondo 15 codos de agua.

Abajo, en el centro: LAS MEDIDAS DESTA PUENTE ESTAN EN LAS PUNTAS DEL COMPAS. Abajo, hacia la izquierda: Alardo de Popma fecit Andres de Oviedo Inventor. 


\section{Transcripción de la clave:}

A. La Planta de los fundamentos desta Puente.

B. Las estacadas que a de llevar el fundamento desta fabrica.

C. La Planta de los Pilastrones.

D. Lo que tiene de grueso cada Pilar.

E. Lo que tienen los arcos de claro de ancho y alto.

F. Dos subidas que a de tener la Puente ambas en la Parte de Triana.

G. Dos Canales que haze el Río y su hondura.

$\mathrm{H}$. La ysleta que haze el Rio enfrente las quebas.

I. La torre del Oro y postigo del carvon.

L. El Muelle.

M. El Pasaxe de los barcos de Sevilla a Triana.

N. Donde se vende la Cal y ladrillo.

O. Donde se vende la Sardina.

P. Donde se vende la fruta y Melones.

Q. La Yglesia de Señora Santa Ana.

R. El Castillo de Triana.

S. La Almona.

T. La Calle de la Cava.

V. Cerro donde se ponen los pinos de Segura.

Tipo

Medidas

Grabado calcográfico

$315 \times 410 \mathrm{~mm}$

Ubicación y signatura Archivo Municipal de Sevilla, XI-38 (Fol.)-14, fol. 37

Como bien apunta María Dolores Cabra Loredo en su magnífica aportación Iconografía de Sevilla. Tomo primero. 1400-1650 (1988), el grabado se encuentra perfectamente documentado sin necesidad de ahondar en aspectos técnicos, permitiéndose el lujo de mostrar parte de la actividad económica que en aquel momento giraba en torno al Guadalquivir. No deja de llamarnos la atención, como ya advierte esta historiadora, la inusual perspectiva de la ciudad que muestra; totalmente diferente a la reproducida hasta ahora. Basta con darse cuenta de que, acostumbrados a las vistas desde el Aljarafe con el río, el Arenal y la Giralda como protagonistas, este último elemento se omite, centrando su atención en el puerto. 


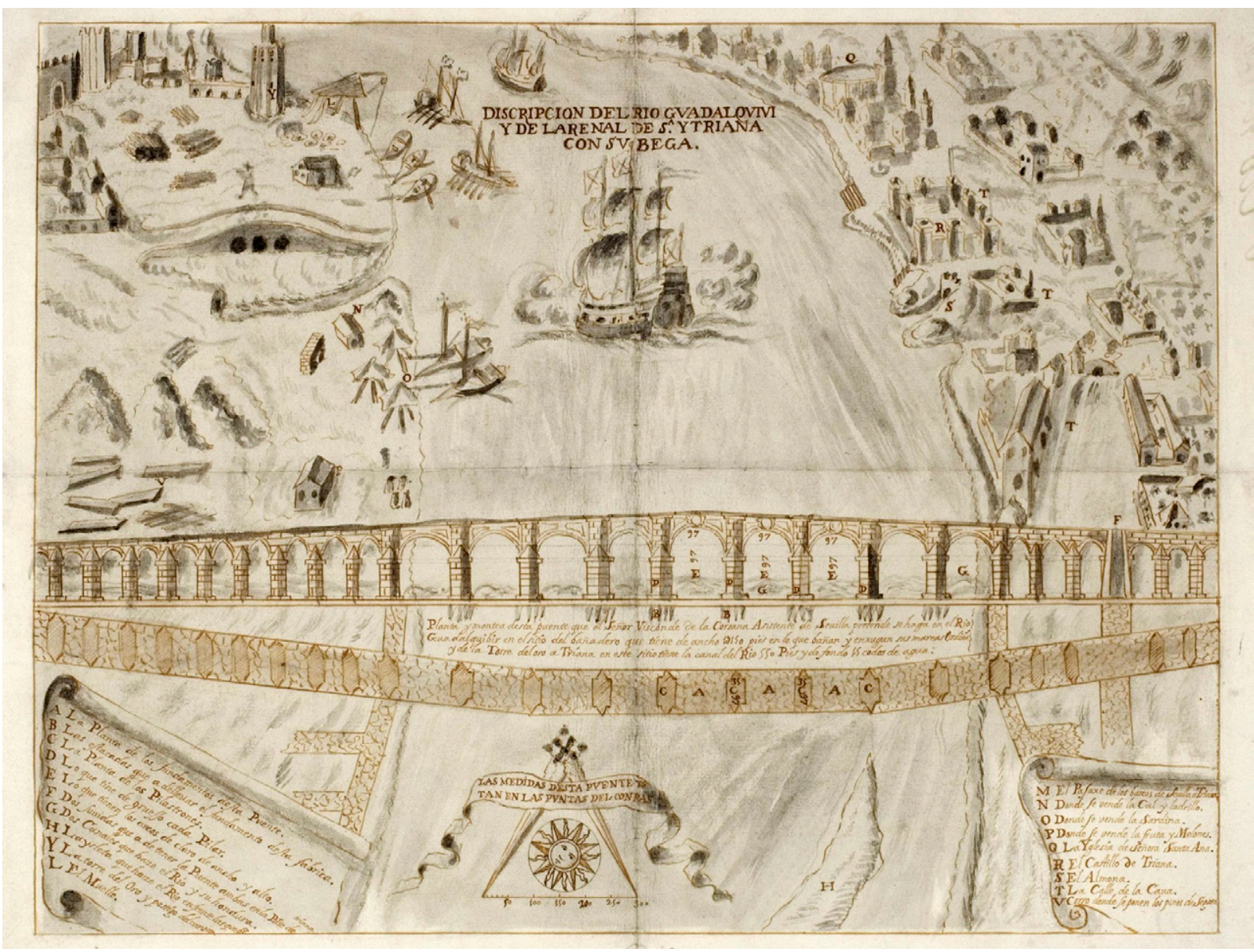

Fig. 2. Proyecto de un puente entre Sevilla y Triana. (¿1696?), Archivo Municipal de Sevilla, PI. I-1-23.

$\begin{array}{ll}\text { Título } & \text { Proyecto de un puente entre Sevilla y Triana (Fig. 2) } \\ \text { Fecha } & \dot{\imath} 1696 ? \\ \text { Autor/es } & \text { Anónimo, copia del dibujo de Andrés de Oviedo } \\ \text { Leyenda y transcripción } & \text { La misma que en el original } \\ \text { Tipo } & \text { Dibujo a pluma con tinta sepia y aguada gris } \\ \text { Medidas } & 310 \times 400 \mathrm{~mm} \\ \text { Ubicación y signatura } & \text { Archivo Municipal de Sevilla, Pl. I-1-23 }\end{array}$

Para terminar, del dibujo que realizara Andrés de Oviedo, del cual se hicieron muchas copias, parece que solo queda un ejemplar depositado en el Archivo Municipal, como apuntan algunos estudiosos del tema. Sancho Corbacho asegura que, de un original perteneciente a Bartolomé Pérez, caballero veinticuatro de la ciudad, se realizó una copia que apareció en una obra (¿1696?) del canónigo y bibliógrafo Ambrosio José de la Cuesta y Saavedra $^{57}$, y que a continuación reproducimos. Sin embargo, a este impreso habría que añadir otro original, citado pero perdido, del historiador Joaquín Guichot, lo que haría un total de tres el número de ejemplares localizados. 
ACOSTA DOMÍNGUEZ, Vicente, Triana. De puente a puente (1147-1853). Relación de acontecimientos históricos, religiosos y populares, ocurridos desde los albores del barrio de Triana, hasta la apertura del puente de Isabel II, Sevilla, Imprenta Escandón, 1979.

ALONSO FRANCO, Eugenio (coord.), Los puentes sobre el Guadalquivir en Sevilla, Sevilla, Colegio de Ingenieros de Caminos, Canales y Puertos, 1999.

ARANA VARFLORA, Fermín, Compendio histórico descriptivo de la muy noble y muy leal ciudad de Sevilla, metrópoli de Andalucía (Parte primera), Sevilla, Editorial Maxtor Librería, 2008.

AZNAR VALLEJO, Eduardo, "Barcos y barqueros en Sevilla", Historia. Instituciones. Documentos, n. ${ }^{\circ}$ 21, 1994, págs. 1-12.

BABÍO WALL, Manuel, Aproximación etnográfica del puerto y río de Sevilla en el siglo XVI, Sevilla, Editorial Don Quijote (Los Libros del Caballero de La Sierpes), 1990.

BORJA PALOMO, Francisco de, Historia crítica de las riadas de Sevilla. Tomo I, Sevilla, Área de Cultura y Fiestas Mayores del Ayuntamiento de Sevilla (Colección Clásicos Sevillanos), 2001.

CABRA LOREDO, María Dolores (con la colaboración Elena María Santiago Pérez), Iconografía de Sevilla, Tomo primero, 1400-1650, Sevilla, FOCUS (Fundación Fondo de Cultura de Sevilla), 1988.

CARRASCO, Diego (coord.), El río, el Bajo Guadalquivir, Sevilla, Equipo 28 (Edición patrocinada por la Delegación de Cultura del Ayuntamiento de Sevilla y la Consejería de Cultura y la de Política Territorial de la Junta de Andalucía), 1985.

CASTILLO MARTOS, Manuel y RODRÍGUEZ MATEOS, Joaquín, Sevilla barroca y el siglo XVII, Sevilla, Editorial Universidad de Sevilla, 2017.

DE ARIÑO, Francisco, Sucesos de Sevilla de 1592 a 1604, Sevilla, Colegio Oficial de Aparejadores y Arquitectos Técnicos de Sevilla, 2005.

DEL MORAL ITUARTE, Leandro, El Guadalquivir y la transformación urbana de Sevilla (Siglos XVIII-XX), Sevilla, Ayuntamiento de Sevilla (Biblioteca de Temas Sevillanos), 1992.

DOMINGUEZ ORTIZ, Antonio, Historia de Sevilla. La Sevilla del siglo XVII, Sevilla, Publicaciones de la Universidad de Sevilla (Colección de Bolsillo, Historia de Sevilla), 1984.

DOMINGUEZ ORTIZ, Antonio, Orto y Ocaso de Sevilla. Estudio de la prosperidad y decadencia de la ciudad durante los siglos XVI y XVII, Córdoba, Diputación Provincial de Sevilla, 2003.

ESCALANTE DE MENDOZA, Juan, Itinerario de Navegación de los Mares y Tierras Occidentales, 1575, Madrid, Museo Naval, 1985.

GARCÍA GÓMEZ, Emilio y LÉVI-PROVENÇAL, Évariste, Sevilla a comienzos del siglo XII. El tratado de Ibn 'Abdun, Sevilla, Área de Cultura del Ayuntamiento de Sevilla (Biblioteca de Temas Sevillanos), 1992.

LADERO QUESADA, Miguel Ángel, Historia de Sevilla. La ciudad medieval, Sevilla, Publicaciones de la Universidad de Sevilla (Colección de Bolsillo), 1980.

MORALES PADRÓN, Francisco, Historia de Sevilla. La ciudad del Quinientos, Sevilla, Universidad de Sevilla (Colección de Bolsillo), 1989.

MORALES PADRÓN, Francisco, Sevilla y el Río, Sevilla, Servicio de Publicaciones del Ayuntamiento de Sevilla (Biblioteca de Temas Sevillanos), 1980.

MORALES PADRÓN, Francisco, Memorias de Sevilla: (1600-1678), Sevilla, Publicaciones del Monte de Piedad y Caja de Ahorros de Córdoba (Colección Mayor), 1981. 
ORTIZ DE ZUÑIGA, Diego, (Ilustrados y corregidos por Antonio María Espinosa y Carzel), Anales eclesiásticos y seculares de la muy noble y muy leal ciudad de Sevilla, metrópoli de Andalucía, Sevilla, Guadalquivir, 1988.

PÉREZ AGUILAR, Francisco, El puente de barcas de Sevilla (1171-1852) y puentes de barcas de Sevilla y Cádiz, Sevilla, Los Libros de Umsaloua, 2014.

RUBIALES TORREJÓN, Javier (coord.), Historia Gráfica del Puerto de Sevilla, Sevilla, Junta del Puerto de Sevilla y Equipo 28, 1989.

RUÍZ PÉREZ, Pedro, El "Razonamiento de la navegación del Guadalquivir" de Fernán Pérez de Oliva, Córdoba, Ediciones La Posada, 1988.

SALAS, Nicolás de Jesús, Sevilla y sus puentes, Sevilla, Guadalturia Ediciones, 2009.

SANCHÍS RAMÍREZ, José Pascual, "La natación higiénica en el río Guadalquivir en el siglo XIX”, Espacio y Tiempo: Revista de Ciencias Humanas, n. ${ }^{\circ} 22$, 2008, págs. 233-246.

SANCHO CORBACHO, Antonio (selección y notas), Iconografía de Sevilla, Sevilla, Gráficas del Sur (por cuenta de Abengoa, S.A. Montajes Eléctricos), 1975.

VALOR PIECHOTTA, Magdalena y TAHIRI, Ahmed, Sevilla Almohade, Sevilla-Rabat, Fundación las Tres Culturas del Mediterráneo, Universidad de Sevilla, Junta de Andalucía (Consejería de Obras Públicas y Transportes), Ayuntamiento de Sevilla (Gerencia de Urbanismo) y Universidad Hassán II de Mohammedia (Facultad de Letras), 1999. 